\title{
TINJAUAN KONSEP PEDESTRIAN FRIENDLY DI LINGKUNGAN FAKULTAS TEKNIK UNIVERSITAS SRIWIJAYA
}

\author{
Dessy Syarlianti ${ }^{1}$, Abdurrachman Arief ${ }^{2}$ \\ 1. Program Studi Arsitektur Fakultas Teknik Universitas Sriwijaya \\ Jl. Raya Palembang - Prabumulih Km 32, Ogan Ilir, Sumatera Selatan \\ 2. Program Studi Arsitektur Fakultas Teknik Universitas Sriwijaya \\ Jl. Raya Palembang - Prabumulih Km 32, Ogan Ilir, Sumatera Selatan \\ dessysyarlianti@gmail.com
}

\begin{abstract}
Abstrak
Lingkungan Fakultas Teknik Universitas Sriwijaya merupakan bagian dari skenario pengembangan Masterplan Universitas Sriwijaya. Dengan adanya perubahan visi dan misi Universitas mengakibatkan pula perubahan aktifitas serta fasilitas dan tata bangunan yang ada. Konsep Pedestrian Friendly merupakan salah satu konsep yang menjawab persoalan umum yang ada saat ini, isu sustainability, efisiensi energi, sekaligus menjadi usaha untuk memanusiakan kembali kawasan yang semakin lama berorientasi pada kendaraan bermotor. Orientasi pembangunan dan penataan kawasan seharusnya mempertimbangkan skala manusia sebagai standar, terutama untuk pencapaian di dalam sebuah kampus. Dengan observasi dan analisis di lapangan didapatkan beberapa persoalan terkait penerapan konsep tersebut. Metode Ends-mean membantu mengklasifikasikan persoalan yang ada sehingga menjadi sebuah konsep pedestrian friendly yang kontekstual.
\end{abstract}

kata kunci : pedestrian friendly, Fakultas Teknik, metode ends-mean, Unsri, Indralaya

\begin{abstract}
Title : Review of Pedestrian Friendly Concept in Engineering Faculty Area of Sriwijaya University

The Engineering Faculty is part of Sriwijaya University Masterplan development scenario. The change of the vision and mission of the University has caused amendment to the activities, facilities and also the existing building structure. Pedestrian Friendly Concept is a concept that could answers common problems of the existing Engineering Faculty Design, such as the issue of sustainability, energy efficiency, as well as a re-attempt to humanize region-oriented vehicle. Orientation and arrangement of the siteplan should consider the human scale, especially for achievement within a campus. The purpose of this observation and analysis is to obtained several issues related to the implementation of the concept. Ends-mean method helps classify the existing problems so that it becomes a contextual pedestrian-friendly concept.
\end{abstract}

Keywords : pedestrian friendly, Engineering Faculty, ends-mean methods, Unsri, Indralaya

\section{Pendahuluan}

Berjalan kaki memberikan manfaat tidak hanya untuk kesehatan individu dan pengurangan polusi, namun juga menjadi usaha untuk mendekatkan diri pada lingkungan. Jacobs (1993) menyatakan jalan yang selalu dikenang, menimbulkan kesan yang kuat dan positif merupakan jalan yang 
baik dan ideal. Kesan tersebut dinikmati perlahan-lahan secara terus menerus sehingga menimbulkan efek positif terhadap perilaku penggunanya.

Jalan tidak hanya merupakan jalur transportasi semata, namun juga berfungsi sebagai ruang publik tempat bersosialisasi dan dapat menarik banyak kegiatan lainnya. Pedestrian friendly adalah suatu konsep perancangan yang mempertimbangan pengguna pejalan kaki sebagai hal yang utama. Pentingnya konsep ini diterapkan dalam perencanaan suatu kawasan adalah untuk meningkatkan efesiensi dan efektifitas kegiatan yang berlangsung di dalamnya sekaligus juga menjawab isu penghematan energi yang berkembang saat ini.

Penerapan konsep pedestrian friendly terkait dengan kenyamanan pencapaian oleh pejalan kaki. Dalam penelitian ini, objek pengamatan adalah lingkungan Fakultas Teknik Unsri. Pengamatan dilakukan sebagai bagian dari pertimbangan evaluasi master plan kampus Indralaya Unsri secara keseluruhan, mengingat bahwa selama 19 tahun terakhir perkembangaan kebutuhan dan program yang dilakukan sudah meningkat sedangkan Master plan kampus Indralaya Universitas Sriwijaya yang dibangun pada tahun 1995 belum pernah dilakukan evaluasi.

Persoalan utama dari penelitian ini adalah tidak terlihatnya perencanaan yang berkesinambungan dan berpihak pada pedestrian pada lingkungan Fakultas Teknik kampus Indralaya Universitas Sriwijaya. Ditinjau dari hubungan terhadap fasilitas di luar lingkungan FT (Fakultas Teknik) sendiri, tidak adanya jalur penghubung yang baik dari Fakultas Teknik menuju bangunan pendukung lain, seperti Gedung Rektorat, Gedung Lembaga
Penelitian, Terminal Kampus dan lainnya. Pada lingkungan FT sendiri, koneksi antar bangunan kurang terintegrasi dengan baik. Sehingga berdasarkan hal tersebut perlu dilakukan tinjauan lebih lanjut mengenai konsep pedestrian friendly pada lingkungan Fakultas Teknik kampus Indralaya sebagai bagian pertimbangan evaluasi masterplan Universitas Sriwijaya di masa yang akan datang.

\section{Elemen Perancangan \\ Arsitektur dalam Konsep Pedestrian Friendly}

\section{Pengertian}

Dalam Meyers (2009), untuk merancang sebuah lingkungan dengan konsep pedestrian friendly dapat mempertimbangkan tiga hal ini:

1. Fasilitas harus berada dalam jarak berjalan kaki dari tempat tinggal atau tempat parkir

2. Kombinasi rute dan tujuan di seluruh daerah harus aman dan mendukung (ramah) pejalan kaki. Pejalan kaki harus merasa nyaman berjalan dari satu tempat ke yang berikutnya dan kemudian akhirnya kembali ke tempat semula

3. Area harus menarik bagi pejalan kaki dengan disajikan rute yang aman dan nyaman.

\section{Elemen Perancangan dalam Konsep Pedestrian Friendly}

Berdasarkan Meyers (2009) dapat diperhatikan beberapa elemen perancangan dalam mendisain kawasan dengan konsep pedestrian friendly, yaitu: site planning, sirkulasi, massa bangunan, proporsi, material, ritme, transparansi, dan detail 


\section{Metode Penelitian}

Penelitian ini merupakan penelitian kualitatif dengan metode deskriptif analisis. Haryanto (2012) dari http://belajarpsikologi.com/pendekatan -jenis-dan-metode-penelitianpendidikan/ pada 09 Februari 2014 menyatakan bahwa penelitian tersebut adalah penelitian yang memusatkan perhatian kepada masalah-masalah aktual sebagaimana adanya pada saat penelitian berlangsung. Melalui penelitian ini, peneliti berusaha mendeskripsikan peristiwa dan kejadian yang menjadi pusat perhatian tanpa memberikan perlakukan khusus terhadap peristiwa tersebut. Variabel yang diteliti adalah kondisi eksisting lingkungan FT Unsri Indralaya yang dikaitkan dengan teori yang didapatkan dari studi literatur mengenai konsep pedestrian friendly. Tujuan penggunaan metode ini agar dapat membuat deskripsi secara sistematis, faktual dan akurat mengenai konsep pedestrian friendly di lingkungan Fakultas Teknik Universitas Sriwijaya Kampus Indralaya, serta dapat menjadi pertimbangan dalam evaluasi masterplan Universitas Sriwijaya ke depannya.

Ruang lingkup dan batasan penelitian ini adalah :

1. Lingkup wilayah atau area penelitian

Area penelitian meliputi Fakultas

Teknik Kampus Indralaya

Universitas Sriwijaya.

2. Lingkup materi penelitian

Lingkup materi penelitian

diarahkan untuk merumuskan

konsep pedestrian friendly yang

kontekstual terhadap lingkungan

Fakultas Teknik Universitas

Sriwijaya.
Penelitian dilakukan dengan tahapan:

a. Membuat daftar asumsi sebagai dasar hipotesis dan prosedur, yaitu bahwa konsep pedestrian friendly belum menjadi pertimbangan dalam perencanaan site plan kawasan Fakultas Teknik Universitas Sriwijaya Kampus Indralaya sehingga aktivitas di dalamnya tidak berjalan secara efektif dan efisien.

b. Menyusun kategori untuk mengklasifikasi data studi literatur terkait konsep pedestrian friendly pada perencanaan institusi Pendidikan.

c. Pengamatan langsung pada objek penelitian, yaitu Fakultas Teknik Kampus Indralaya Universitas Sriwijaya untuk mengambil datadata yang diperlukan

d. Melakukan analisis deskriptif terhadap data hasil sehingga dapat dinilai apakah kawasan ini tidak menerapkan konsep perencanaan yang berpihak pada pedestrian, sehingga menyebabkan ketidakefektifan dan ketidakefisienan aktivitas di dalamnya.

e. Mengidentifikasi persoalan dan potensi dalam penerapan konsep pedestrian friendly pada lingkungan FT Unsri

f. Membuat klasifikasi persoalan dengan metode Ends mean

g. Merumuskan konsep pedestrian friendly yang kontekstual terhadap kawasan Fakultas Teknik Universitas Sriwijaya Kampus Indralaya

h. Membuat kesimpulan hasil temuan 
Tinjauan Fakultas Teknik Universitas Sriwijaya Terhadap Pedestrian Friendly

\section{Master Plan Universitas Sriwijaya}

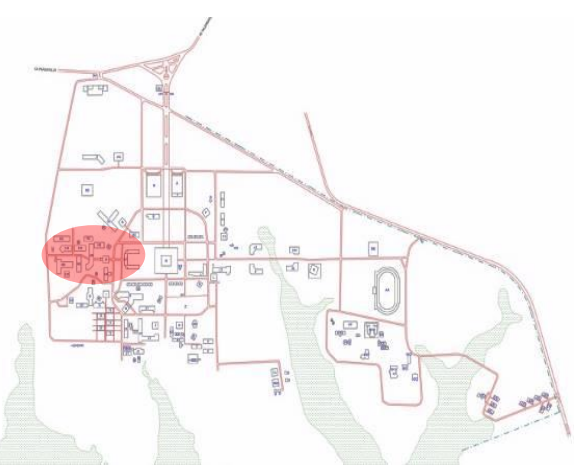

Gambar 1. Master plan Universitas Sriwijaya dan lokasi Fakultas Teknik Sumber: Unit layanan pengadaan Universitas Sriwijaya, 2014

Kampus Utama Indralaya dengan luas 712 hektar terletak 38 kilometer ke arah selatan kota Palembang, merupakan Pusat Kegiatan Pendidikan untuk jenjang Sarjana (S1). Di kampus Indralaya juga terdapat Kantor Pusat Administrasi (KPA), Perpustakaan Pusat, Lembaga Bahasa, Lembaga Penelitian, Lembaga Pengabdian Kepada Masyarakat, Pusat Komputer, Pusat Kegiatan Mahasiswa, Pusat Kesehatan Komunitas. (gambar 1)

Fakultas Teknik Universitas Sriwijaya

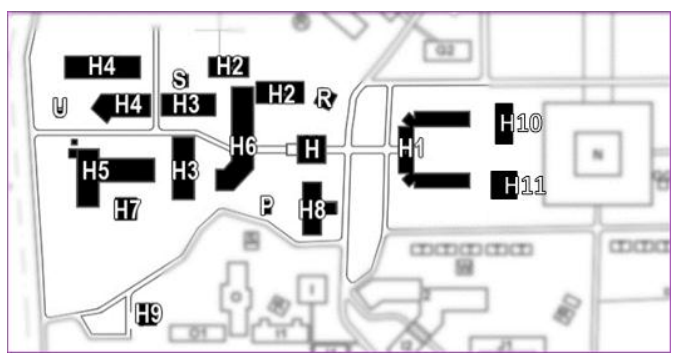

Gambar 2. Peta figure ground pada Fakultas Teknik Unsri Sumber : Analisis, 2014
Berdasarkan pengamatan dan wawancara, batas lingkup wilayah pengembangan Fakultas Teknik tidak terdefinisi dengan jelas (gambar 2), sehingga luasan wilayah FT Unsri belum dapat ditentukan dengan pasti. Berikut pembahasan lingkungan FT Unsri berdasarkan elemen perancangan konsep pedestrian friendly menurut Meyers (2009):

\section{Site Planning}

1. Site Planning and Context

Fakultas Teknik tidak memiliki tema/konteks khusus sehingga tidak memiliki identitas/karakter yang kuat sebagai bangunan pendidikan, yang menyebabkan tidak adanya suguhan pengalaman ruang dengan kesan/karakter tertentu bagi pejalan kaki.

\section{Site Planning and Connectivity} Beberapa hal yang harus ada dalam perencanaan tapak yang bersifat pedestrian friendly adalah:

- Semua sirkulasi kendaraan, sepeda, maupun pejalan kaki, harus memiliki hubungan yang baik sehingga memastikan konektivitas dari dan ke bangunan.

- Keberadaan sidewalks, walkways, intersections, crosswalks, signage, landscaping, dan lighting harus sudah disadari sejak membuat masterplan 


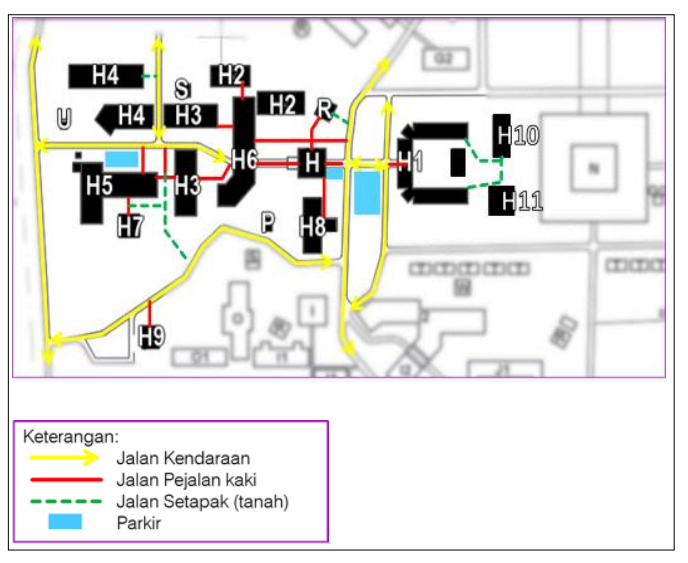

Gambar 3. Peta sirkulasi pada Fakultas Teknik Unsri

Sumber : Analisis, 2014

Berdasarkan hasil pengamatan didapatkan bahwa :

- Tidak adanya elemen-elemen pedestrian yang jelas dan terencana seperti ; jalur khusus sepeda, sidewalks, intersections, crosswalks, signage, landscaping, dan lighting mengakibatkan pejalan kaki tidak nyaman ketika memasuki kawasan Fakultas Teknik (gambar 4)

- Pejalan kaki kesulitan mengakses tiap-tiap bangunan karena banyaknya akses antar bangunan yang tidak terencana bahkan terputus (gambar 3)

- Pergerakan pejalan kaki tidak terarah disebabkan tidak adanya signage (penanda) yang jelas
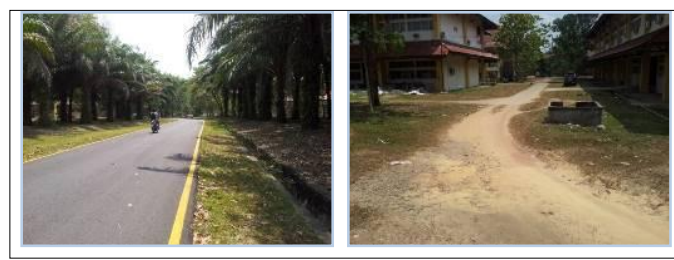

Gambar 4. Beberapa kondisi jalur sirkulasi pada Fakultas Teknik Unsri

Sumber : Observasi, 2014

\section{Site Planning and Parking}

Berdasarkan hasil pengamatan, didapatkan bahwa :

- Hampir semua area parkir yang ada di kawasan Fakultas Teknik berada didepan gedung sehingga memberikan kesan bangunan yang jauh dan sulit dijangkau oleh pejalan kaki

- Sebagian area parkir berada di sisi jalan (on street) ataupun berada di area jalur pejalan kaki menyebabkan terganggunya akses pejalan kaki tersebut

\section{Sirkulasi}

1. Sirkulasi dan Sidewalks

Beberapa hal yang harus dipertimbangkan dalam perencanaan sirkulasi dalam tapak yang pedestrian friendly adalah:

- Sidewalk harus bersambung dari blok satu ke blok lainnya, zona satu ke zona lainnya.

- Sidewalk harus menyediakan rute yg bebas hambatan, langsung serta lebar yg cukup untuk menampung pejalan kaki

Berdasarkan pengamatan, didapatkan bahwa tidak terdapat sidewalk yang jelas sepanjang jalan didalam kawasan fakultas teknik sehingga hal ini dapat membahayakan keselamatan pejalan kaki yang bersebelahan dengan jalur kendaraan bermotor, dikarenakan pejalan kaki dapat langsung berinteraksi dengan kendaraan

2. Sirkulasi dan Persimpangan

Dari hasil pengamatan didapatkan bahwa hampir setiap persimpangan yang ada di Fakultas Teknik membentuk sudut 90 derajat yang artinya tidak adanya radius putar. 
3. Sirkulasi dan Penyeberangan

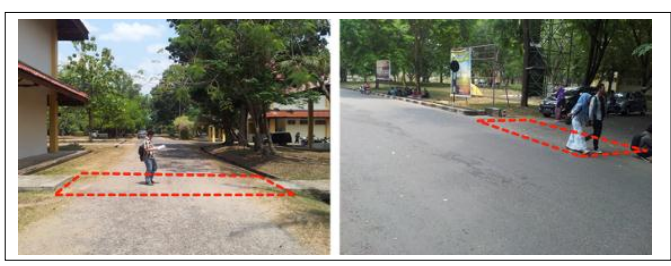

Gambar 5. Kondisi penyeberangan pada Fakultas Teknik Unsri

Sumber : Observasi, 2014

Dari hasil pengamatan, didapatkan bahwa: Tidak adanya tanda pada tempat penyeberangan menyebabkan pejalan kaki sulit mengenali dimana tempat untuk menyeberang (Gambar 5)

4. Sirkulasi dan daerah Penyangga Jalur kendaraan dan jalur pejalan kaki harus memiliki batas yang jelas misalnya dengan penggunaan bollard, pohon tepi jalan, batas parkir, street furniture atau lampu jalan

\section{Massa bangunan}

1. Massa Bangunan dan Skala Manusia Massa bangunan sebaiknya menyesuaikan dengan skala manusia, sehingga tidak terjadi perbedaan ukuran yang terlalu mencolok antara bangunan dan pejalan kaki. Bangunan yang ada di kawasan FT hampir seluruhnya merupakan bangunan diatas 2 lantai (Gambar 6)

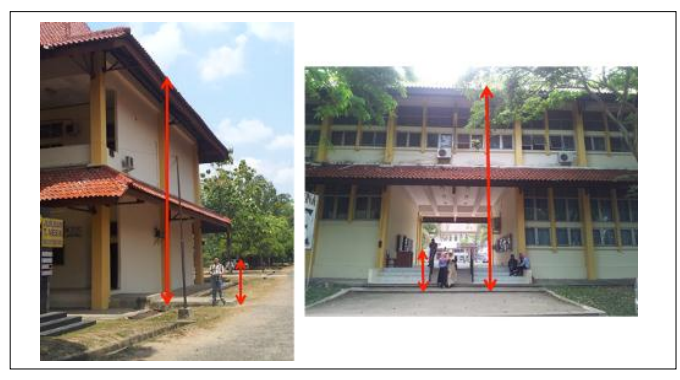

Gambar 6. Foto perbedaan ketinggian manusia dan bangunan pada Fakultas Teknik Unsri

Sumber : Observasi, 2014
2. Massa dan Lantai dasar

Dasar bangunan pada umumnya mengekspose tiang tiang struktur (Gambar 7) serta sudut-sudut dinding bangunan sebagai upaya interaksi bangunan terhadap pejalan kaki.

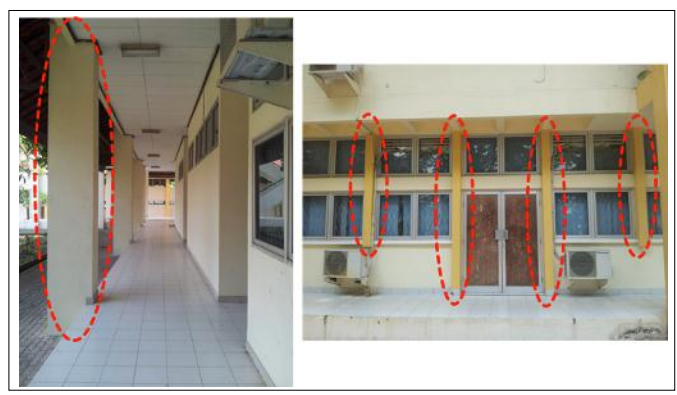

Gambar 7. Penggunaan unsur tiang pada Fakultas Teknik Unsri

Sumber : Observasi, 2014

\section{Massa dan Kepadatan}

Kerapatan dan variasi elemenelemen bangunan yaitu dengan membuat fasad bangunan menjadi bagian-bagian yang lebih kecil dapat membuat pejalan kaki menjadi lebih nyaman

Dari hasil pengamatan, didapatkan bahwa :

- Sebagian besar bangunan merupakan bangunan dengan dimensi yang cukup panjang, lebar, tinggi dan masif

- Sebagian besar fasad bangunan cenderung datar dan berupa dinding yang lebar (Gambar 8)

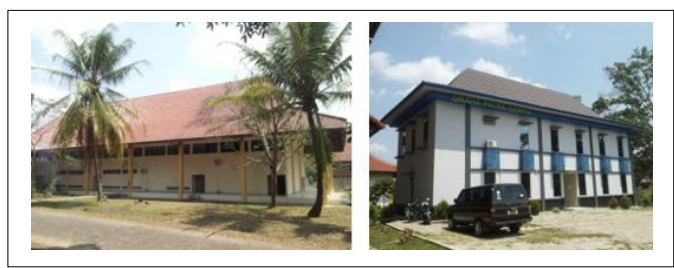

Gambar 8. Kerapatan dan variasi elemenelemen bangunan pada FT Unsri Sumber : Observasi, 2014 


\section{Proporsi}

1. Proporsi dan kedalaman blok

Semakin banyak persimpangan antar blok membuat jalur pejalan kaki menjadi lebih nyaman karena pejalan kaki mendapatkan pengalaman ruang yang lebih banyak, mudah untuk berpindah blok, serta dapat memperlambat kendaraan

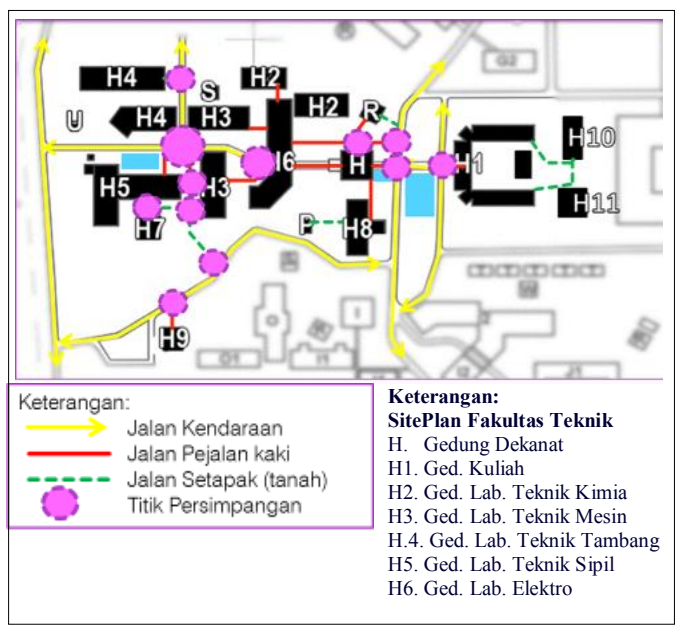

Gambar 9. Peta sirkulasi dan persimpangan pada FT Unsri

Sumber : Observasi, 2014

Dari hasil pengamatan, didapatkan bahwa Sistem penataan bangunan yang organik menyebabkan tidak terbentuknya blok-blok bangunan, namun tetap memiliki banyak persimpangan (Gambar 9)

2. Proporsi dan Orientasi terhadap Jalan

Rasio antara tinggi bangunan dan lebar jalan didepannya berpengaruh terhadap lingkup visual bagi pedestrian. Semakin lebar jalan, maka akan semakin besar pula lingkup visual yang akan didapatkan oleh pejalan kaki terhadap bangunan tersebut (Gambar 10)

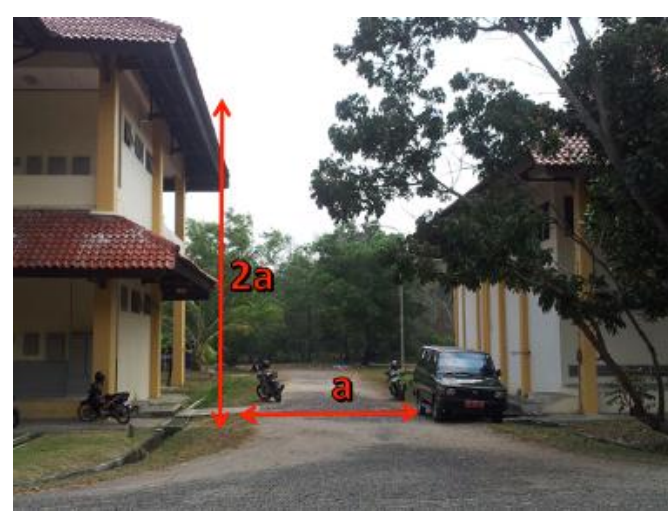

Gambar 10. Foto rasio ketinggian bangunan dan lebar jalan pada Fakultas Teknik Unsri Sumber: Observasi, 2014

Dari hasil pengamatan, didapatkan bahwa rasio antara tinggi bangunan dan lebar jalan cukup jauh, dimana lebar jalan hanya setengah atau sepertiga dari tinggi bangunan.

3. Proporsi dan Disain Fasad

Proporsi elemen arsitektural pada fasad bangunan berpengaruh terhadap visual pejalan kaki, elemen 2 arsitektural seperti awning, pintu, jendela, kolom yang terlalu banyak dapat merusak visual pejalan kaki

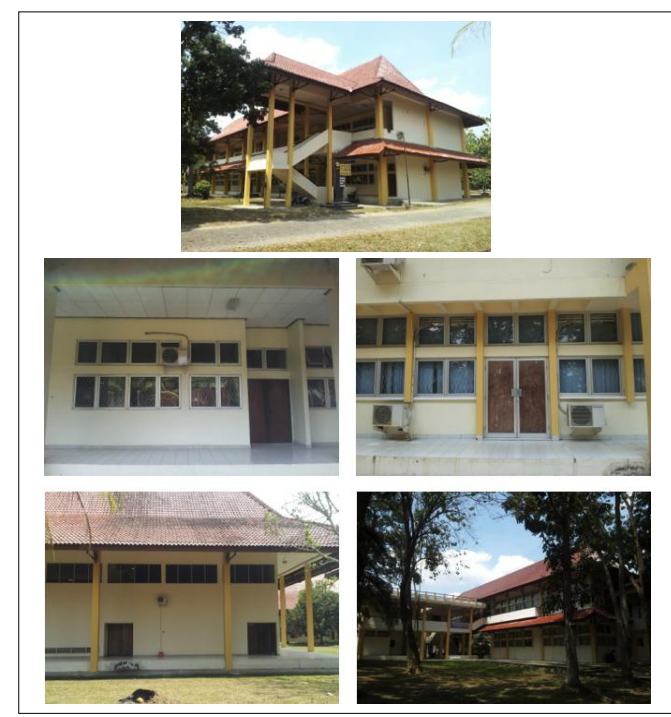

Gambar 11. Elemen pada fasad bangunan FT Unsri

Sumber: Observasi, 2014 
Dari hasil pengamatan, didapatkan bahwa:

- Bangunan-bangunan di kawasan Fakultas Teknik memiliki fasad dengan pola yang hampir sama, dimana banyak menggunakan pintu dan jendela alumunium.

- Bangunan banyak menggunakan elemen berupa tiang-tiang pada fasad bangunan, baik tiang struktur maupun non struktur

- Penggunaan elemen jendela, pintu, dan tiang yang berulangulang pada hampir seluruh bangunan yang ada di dalam kawasan (gambar 11)

4. Proporsi dan Penanda

Signage (penanda) harus diletakkan pada tinggi yang tepat sehingga terlihat jelas dan mudah dibaca oleh pejalan kaki. Dari hasil pengamatan, didapatkan bahwa tinggi signage (penanda) pada kawasan Fakultas Teknik berkisar diantara $2 \mathrm{~m}-3 \mathrm{~m}$ dari permukaan tanah/lantai. (gambar 12)

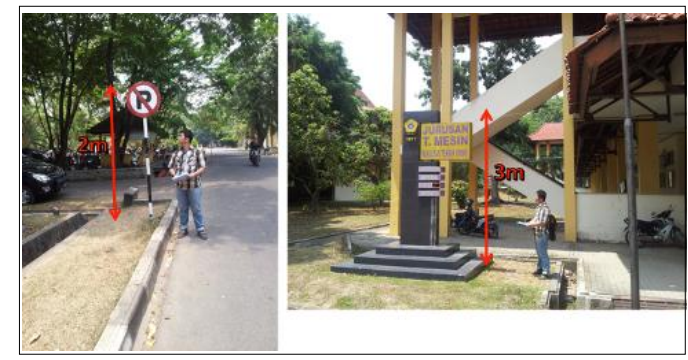

Gambar 12. Signage pada lingkungan FT Unsri

Sumber: Observasi, 2014

\section{Material}

Material yang digunakan pada lingkungan FT Unsri tidak beragam, baik berupa jalan aspal perkerasan dan paving block. Elemen eksternal seperti penanda, lanskap, pagar, bangku taman, kebun, sculpture, artwork, tidak ditemui pada lingkungan FT Unsri Indralaya, hanya terdapat penanda kawasan berupa tugu FT Unsri. (gambar 13)

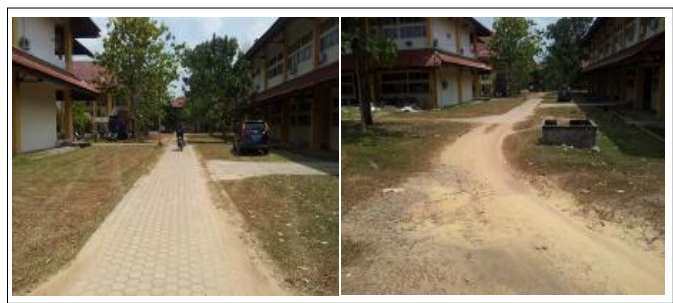

Gambar 13.Kondisi material jalur pedestrian FT Unsri

sumber : Observasi, 2014

\section{Ritme}

Pola repetisi terlihat dari pengulangan modul kolom bangunan, namun tidak menerus antara satu bangunan dengan bangunan lain sehingga kemenerusan irama kurang terbaca oleh pedestrian. (Gambar 14)

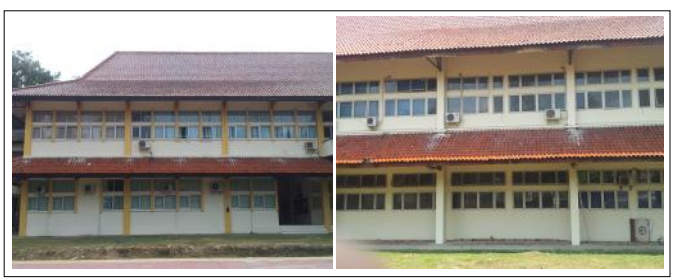

Gambar 14. Ritme pada bangunan laboratorium FT Unsri

Sumber : Observasi, 2014

\section{Transparansi}

Bangunan di lingkungan FT UNSRI belum menyiratkan koneksi visual. Lantai dasar tidak bersifat transparan, hal ini dikarenakan fungsi bangunan sebagai wadah kegiatan akademik dan membutuhkan privasi. Jendela dan pintu memiliki ukuran standar dan kurang menjaga visual connectivity bagi pedestrian.

\section{Detail}

Tidak ada permainan fasad, ornament, ataupun material dan tekstur yang disajikan bagi pedestrian. Detail street furniture seperti lampu taman, bangku, pagar, tempat sampah yang terdisain, terutama untuk public art tidak terlihat di lingkungan FT UNSRI. 


\section{Analisis Persoalan dan Potensi dalam Penerapan Konsep Pedestrian Friendly di Lingkungan FT Unsri}

Berdasarkan pengamatan yang dilakukan, didapatkan persoalan dan potensi di lingkungan FT Unsri sebagai berikut:

\section{Site Planning}

Persoalan yang didapatkan adalah:

a. Penempatan bangunan tidak saling mendefinisikan ruang luar (outdoor space), sehingga pedestrian tidak dapat membaca kemenerusan ruang luar dan dalam

b. Tidak ada jalur pedestrian atau sepeda yang terdisain dengan baik di dalam lingkungan FT Unsri Indralaya

Sedangkan potensi yang terdapat di lingkungan FT Unsri adalah :

a. Kantong parkir tidak mendominasi bangunan, sehingga bangunan tidak terisolasi dari pedestrian

\section{Sirkulasi}

Persoalan sirkulasi di lingkungan FT Unsri adalah :

a. Tidak ada trotoar yang menerus dari satu bangunan ke bangunan yang lain

b. Tidak terdapat rute trotoar yang langsung dan jelas dari bangunan pengajaran ke bangunan dekanat

c. Tidak terdapat rute trotoar yang jelas dan langsung antar bangunan pengajaran dan masing-masing laboratorium

d. Lebar dan kondisi beberapa trotoar tidak memungkinkan untuk pedestrian berjalan sekaligus mewadahi street furniture e. Tidak adanya penanda penyebrangan/ zebra cross untuk pedestrian, baik berupa pembedaan level/ split level, penggunaan material yang unik, terutama tanda penyeberangan yang jelas.

f. Tidak ada penyeberangan yang terdisain dari kantung parkir menuju ke gedung pengajaran, maupun ke gedung dekanat.

g. Tidak ada bufferl daerah penyangga antar pedestrian dan kendaraan bermotor

h. Tidak ada jalur penghubung yang jelas antara gedung Studio Arsitektur dan gedung Dekanat

i. Tidak ada jalur pehubung antara Graha Patra Kemika dan bangunan lain di lingkungan FT

Potensi sirkulasi yang terdapat di lingkungan FT Unsri adalah :

a. Terdapat jalur penghubung antar bangunan Mushola dan gedung Dekanat

b. Terdapat sky bridge yang mengubungkan gedung Arsitektur dengan gedung Dekanat

c. Terdapat student centre sebagai penghubung dari gedung Dekanat menuju gedung-gedung Laboratorium

d. Parking on street berlaku di lingkungan FT Unsri, karena tidak menyediakan kantung parkir khusus

\section{Massa Bangunan}

Persoalan massa bangunan terkait penerapan konsep pedestrian friendly di lingkungan FT Unsri adalah sebagai berikut :

a. Penambahan massa di lingkungan FT tidak memiliki ketentuan, misal Graha Patra Kemika dan Gedung Studio Arsitektur

b. Tidak terdapat stimulus visual pada bagian lantai dasar 
bangunan, seperti jalur pejalan kaki yang tertutup, bentuk yang irregular, sudut bangunan, dan lainnya.

c. Massa bangunan kurang kuat mendefinisikan jalur pejalan kaki.

Potensi massa bangunan di lingkungan FT Unsri :

a. Bangunan masih memperhatikan skala manusia, hal ini terlihat dari permainan solid dan void yang banyak terdapat di bangunan pengajaran dan laboratorium.

b. Ukuran dan penempatan jendela dan pintu pada masing-masing bangunan mempertimbangkan skala manusia

\section{Proporsi}

Persoalan

a. Ratio jalan dan tinggi bangunan yang mampu membuat visual enclosure bagi pedestrian adalah bangunan dekanat dan jalan di depannya.

b. Penempatan penanda (signage) yang kurang nyaman bagi pedestrian. (gambar 15)

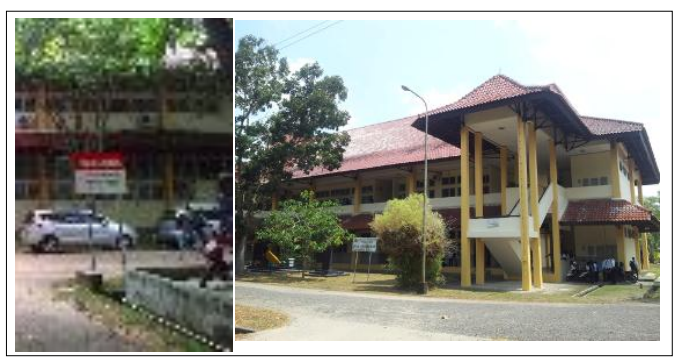

Gambar 15. Penempatan signage yang mengganggu pedestrian dan visual enclosure kurang tercipta dari jalan di depan bangunan lab Teknik Pertambangan Sumber : Observasi, 2014

\section{Potensi}

a. Blok bangunan sesuai dengan proporsi dengan lebar kurang dari $150 \mathrm{~m}$, sehingga jarak tempuh masih nyaman untuk pedestrian b. Disain fasad bangunan dekanat, pengajaran dan laboratorium mempertimbangkan skala manusia

\section{Material}

a. Tidak terdapat penggunaan material unik dan khusus pada jalur pedestrian maupun pada bangunan, sehingga tidak menciptakan pengalaman meruang bagi pedestrian.

b. Tidak ada street furniture yang terdisain, seperti bangku taman, pagar, sculpture, dan lain-lain

\section{Ritme}

a. Bangunan tidak saling
memperkuat ruang luar, meskipun menggunakan pola yang sama, dikarenakan penempatan massa yang tidak saling berkesinambungan

b. Ritme yang digunakan cenderung monoton.

\section{Transparasi}

Persoalan:

a. Kondisi bangunan di lingkungan FT Unsri belum menyiratkan koneksi visual.

b. Jendela dan pintu memiliki ukuran standar yang kurang menjaga visual connectivity bagi pedestrian.

c. Posisi bangunan juga tidak membentuk outdoor space, baik bangunan laboratorium maupun bangunan pengajaran, sehingga pedestrian tidak dapat menikmati kemenerusannya.

\section{Detail}

Persoalan

a. Tidak ada permainan fasad, ornament, ataupun material dan tekstur yang disajikan bagi pedestrian.

b. Detail street furniture seperti 
lampu taman, bangku, pagar, tempat sampah yang terdisain, terutama untuk public art tidak terlihat di lingkungan FT Unsri

\section{Klasifikasi Persoalan}

Untuk membuat konsep pedestrian friendly yang kontekstual terhadap lingkungan FT Unsri, perlu dilakukan klasifikasi terhadap persoalan yang telah diidentifikasi. Dengan metode End-Means, persoalan perancangan terbagi ke dalam tiga struktur (Rowe, 1987) yaitu persoalan yang terdefinisi dengan baik (well defined problem), persoalan yang kurang tepat didefinisikan (ill defined problem) dan persoalan yang sulit didefinisikan (wicked problem). Klasifikasi ini berdasarkan pada kemudahan merumuskan persoalan, kejelasan solusi dan caranya. Berdasarkan metode End-means, persoalan pedestrian friendly di lingkungan FT Unsri dapat diklasifikasikan sebagai berikut:

Tabel 1. Klasifikasi Persoalan di lingkungan FT Unsri

\begin{tabular}{|c|c|c|c|}
\hline $\mathrm{NO}$ & Persoalan & $\begin{array}{c}\text { Klasifi- } \\
\text { kasi }\end{array}$ & Saran \\
\hline \multirow[t]{2}{*}{1} & $\begin{array}{l}\text { SITE } \\
\text { PLANNING } \\
\text { a. Penempatan } \\
\text { bangunan tidak } \\
\text { saling } \\
\text { mendefinisikan } \\
\text { ruang luar } \\
\text { (outdoor space) }\end{array}$ & well & $\begin{array}{l}\text { Merenovasi } \\
\text { bangunan di } \\
\text { lingkungan FT } \\
\text { Unsri agar saling } \\
\text { berhubungan dan } \\
\text { menciptakan } \\
\text { ruang luar yang } \\
\text { positif }\end{array}$ \\
\hline & $\begin{array}{l}\text { b. Tidak ada jalur } \\
\text { pedestrian atau } \\
\text { sepeda yang } \\
\text { terdisain } \\
\text { dengan baik di } \\
\text { dalam } \\
\text { lingkungan FT } \\
\text { Unsri }\end{array}$ & well & $\begin{array}{l}\text { Membuat disain } \\
\text { jalur pedestrian } \\
\text { dan sepeda yang } \\
\text { baik }\end{array}$ \\
\hline 2 & $\begin{array}{l}\text { SIRKULASI } \\
\text { Tidak ada trotoar } \\
\text { yang menerus dari } \\
\text { satu bangunan ke } \\
\text { bangunan yang } \\
\text { lain }\end{array}$ & well & $\begin{array}{l}\text { Membuat trotoar } \\
\text { yang menerus dari } \\
\text { satu bangunan ke } \\
\text { bangunan lain }\end{array}$ \\
\hline
\end{tabular}

\begin{tabular}{|c|c|c|c|}
\hline $\mathrm{NO}$ & Persoalan & $\begin{array}{c}\text { Klasifi- } \\
\text { kasi }\end{array}$ & Saran \\
\hline & $\begin{array}{l}\text { Tidak terdapat } \\
\text { rute trotoar yang } \\
\text { langsung dan jelas } \\
\text { dari bangunan } \\
\text { pengajaran ke } \\
\text { bangunan } \\
\text { dekanata. }\end{array}$ & well & $\begin{array}{l}\text { Membuat rute } \\
\text { trotoar dari } \\
\text { bangunan } \\
\text { pengajaran ke } \\
\text { bangunan dekanat } \\
\text { serta } \\
\text { memanfaatkan } \\
\text { jalur penghubung } \\
\text { yang sudah ada }\end{array}$ \\
\hline & $\begin{array}{l}\text { Tidak terdapat } \\
\text { rute trotoar yang } \\
\text { jelas dan langsung } \\
\text { antar bangunan } \\
\text { pengajaran dan } \\
\text { masing-masing } \\
\text { laboratorium }\end{array}$ & well & $\begin{array}{lr}\text { Membuat } & \text { rute } \\
\text { pedestrian } & \text { yang } \\
\text { terdisain } & \text { dari } \\
\text { pengajaran } & \\
\text { menuju } & \text { ke } \\
\text { laboratorium } & \end{array}$ \\
\hline & $\begin{array}{l}\text { Lebar dan kondisi } \\
\text { beberapa trotoar } \\
\text { tidak } \\
\text { memungkinkan } \\
\text { untuk pedestrian } \\
\text { berjalan sekaligus } \\
\text { mewadahi street } \\
\text { furniture }\end{array}$ & well & $\begin{array}{l}\text { Membuat trotoar } \\
\text { dengan lebar min } \\
100 \quad \mathrm{~cm} \text { agar } \\
\text { mampu } \\
\text { menampung } \\
\text { pedestrian dan } \\
\text { street furniture }\end{array}$ \\
\hline & $\begin{array}{l}\text { Tidak adanya } \\
\text { penanda } \\
\text { penyebrangan/ } \\
\text { zebra cross untuk } \\
\text { pedestrian, baik } \\
\text { berupa level/ } \\
\text { pembedaan level, } \\
\text { split yang } \\
\text { penggunaan } \\
\text { material terutama } \\
\text { unik, yanda } \\
\text { tanda } \\
\text { penyeberangan } \\
\text { yang jelas. }\end{array}$ & well & $\begin{array}{l}\text { Membuat penanda } \\
\text { sebagai tempat } \\
\text { penyeberangan, } \\
\text { berupa cat, } \\
\text { pembedaan } \\
\text { ketinggian, } \\
\text { ataupun material } \\
\text { yang unik }\end{array}$ \\
\hline & $\begin{array}{l}\text { Tidak ada } \\
\text { penyeberangan } \\
\text { yang terdisain dari } \\
\text { kantung parkir } \\
\text { menuju ke gedung } \\
\text { pengajaran, } \\
\text { maupun ke } \\
\text { gedung dekanat }\end{array}$ & well & $\begin{array}{l}\text { Membuat tempat } \\
\text { penyeberangan } \\
\text { yang terdisain dari } \\
\text { kantung parkir } \\
\text { menuju bangunan }\end{array}$ \\
\hline & $\begin{array}{l}\text { Tidak ada buffer/ } \\
\text { daerah penyangga } \\
\text { antar pedestrian } \\
\text { dan kendaraan } \\
\text { bermotor }\end{array}$ & well & $\begin{array}{l}\text { Membuat daerah } \\
\text { penyangga antar } \\
\text { jalur pedestrian } \\
\text { dan kendaraan }\end{array}$ \\
\hline & $\begin{array}{lr}\text { Tidak ada } & \text { jalur } \\
\text { penghubung } & \text { yang } \\
\text { jelas } & \text { antara } \\
\text { gedung } & \text { Studio } \\
\text { Arsitektur dan } & \text { gedung Dekanat }\end{array}$ & IIl & $\begin{array}{l}\text { Membuat jalur } \\
\text { penghubung antar } \\
\text { gedung Studio } \\
\text { Arsitektur, } \\
\text { gedung Arsitektur } \\
\text { dan Gedung } \\
\text { Dekanat }\end{array}$ \\
\hline & $\begin{array}{l}\text { Tidak ada jalur } \\
\text { pengubung antara } \\
\text { Graha Patra } \\
\text { Kemika dan } \\
\text { bangunan lain di } \\
\text { lingkungan FT }\end{array}$ & IIl & $\begin{array}{lr}\text { Membuat } & \text { jalur } \\
\text { penghubung } & \text { antar } \\
\text { Graha } & \text { Patra } \\
\text { Kemika } & \text { dan } \\
\text { bangunan } & \\
\text { Dekanat } & \\
\end{array}$ \\
\hline 3 & $\begin{array}{l}\text { MASSA } \\
\text { BANGUNAN } \\
\text { a. Penambahan } \\
\text { massa tidak } \\
\text { mempertim- } \\
\text { bangkan }\end{array}$ & IIl & $\begin{array}{l}\text { Membuat sebuah } \\
\text { guideline untuk } \\
\text { pengembangan } \\
\text { site plan di masa } \\
\text { yang akan datang }\end{array}$ \\
\hline
\end{tabular}




\begin{tabular}{|c|c|c|c|}
\hline \multirow[t]{4}{*}{$\mathrm{NO}$} & Persoalan & $\begin{array}{c}\text { Klasifi- } \\
\text { kasi }\end{array}$ & Saran \\
\hline & $\begin{array}{l}\text { konteks } \\
\text { lingkungan }\end{array}$ & & \\
\hline & $\begin{array}{l}\text { b. Tidak terdapat } \\
\text { variasi stimulus } \\
\text { visual pada } \\
\text { lantai dasar } \\
\text { bangunan }\end{array}$ & well & $\begin{array}{l}\text { Membuat } \\
\text { stimulus visual } \\
\text { pada bangunan, } \\
\text { dengan cara } \\
\text { membuat jalur } \\
\text { pejalan kaki yang } \\
\text { tertutup, bentuk } \\
\text { yang irregular, } \\
\text { memberi detail } \\
\text { pada sudut } \\
\text { bangunan }\end{array}$ \\
\hline & $\begin{array}{l}\text { c. Massa } \\
\text { bangunan } \\
\text { kurang } \\
\text { mendifinisikan } \\
\text { jalur pejalan } \\
\text { kaki }\end{array}$ & Ill & $\begin{array}{l}\text { Redisain fasade } \\
\text { bangunan agar } \\
\text { saling berinteraksi } \\
\text { membentuk ruang } \\
\text { pejalan kaki }\end{array}$ \\
\hline \multirow[t]{2}{*}{4} & $\begin{array}{l}\text { PROPORSI } \\
\text { a. ratio jalan dan } \\
\text { bangunan } \\
\text { kurang } \\
\text { menciptakan } \\
\text { visual } \\
\text { enclosure } \\
\end{array}$ & well & $\begin{array}{l}\text { Mendisain dan } \\
\text { melebarkan } \\
\text { trotoar yang } \\
\text { berhadapan } \\
\text { dengan bangunan, }\end{array}$ \\
\hline & $\begin{array}{l}\text { b. penempatan } \\
\text { signage yang } \\
\text { kurang nyaman } \\
\text { bagi pedestrian }\end{array}$ & well & $\begin{array}{lr}\text { Mengubah } & \text { ukuran } \\
\text { signage } & \text { sesuai } \\
\text { dengan } & \text { skala } \\
\text { manusia, serta } & \text { menempatkannya } \\
\text { dengan baik }\end{array}$ \\
\hline \multirow[t]{2}{*}{5} & $\begin{array}{l}\text { MATERIAL } \\
\text { a. Tidak terdapat } \\
\text { penggunaan } \\
\text { material yang } \\
\text { khusus dan } \\
\text { unik pada jalur } \\
\text { pedestrian dan } \\
\text { bangunan } \\
\text { pembentuk } \\
\text { jalur pedestrian }\end{array}$ & well & $\begin{array}{l}\text { Renovasi fasade } \\
\text { bangunan dan } \\
\text { jalur pedestrian } \\
\text { menggunakan } \\
\text { material unik dan } \\
\text { tekstur khusus }\end{array}$ \\
\hline & $\begin{array}{l}\text { b. Tidak terdapat } \\
\text { street furniture } \\
\text { yang terdisain }\end{array}$ & well & $\begin{array}{l}\text { Menempatkan } \\
\text { street furniture } \\
\text { yang terdisain } \\
\text { dengan baik }\end{array}$ \\
\hline \multirow[t]{2}{*}{6} & $\begin{array}{l}\text { RITME } \\
\text { a. Ritme antar } \\
\text { bangunan tidak } \\
\text { saling } \\
\text { berkesinambun } \\
\text { gan } \\
\end{array}$ & ill & $\begin{array}{lr}\text { Menata ulang } \\
\text { bangunan } \\
\text { saling } \\
\text { berkesinam- } \\
\text { bungan }\end{array}$ \\
\hline & $\begin{array}{l}\text { b. Ritme bangunan } \\
\text { cenderung } \\
\text { monoton }\end{array}$ & well & $\begin{array}{l}\text { Membuat } \\
\text { pemecah irama } \\
\text { bangunan, berupa } \\
\text { entrancer yang } \\
\text { menarik perhatian } \\
\text { atau permainan } \\
\text { warna dan kolom } \\
\text { pada fasad } \\
\text { bangunan }\end{array}$ \\
\hline 7 & $\begin{array}{c}\text { TRANSPARANSI } \\
\text { a. Bangunan tidak } \\
\text { menyiratkan } \\
\text { koneksi visual }\end{array}$ & ill & $\begin{array}{l}\text { Merenovasi fasad } \\
\text { bangunan } \\
\text { terutama pada } \\
\text { lantai dasar, agar } \\
\text { lebih bersifat } \\
\text { transparan untuk } \\
\text { memberikan } \\
\text { koneksi visual }\end{array}$ \\
\hline
\end{tabular}

\begin{tabular}{|c|c|c|c|}
\hline $\mathrm{NO}$ & Persoalan & $\begin{array}{c}\text { Klasifi- } \\
\text { kasi }\end{array}$ & Saran \\
\hline & & & dari ruang luar \\
\hline & $\begin{array}{l}\text { b. ukuran jendela } \\
\text { dan pintu } \\
\text { standar yang } \\
\text { menghalangi } \\
\text { koneksi visual }\end{array}$ & well & $\begin{array}{l}\text { memperlebar } \\
\text { ukuran jendela } \\
\text { dan pintu serta } \\
\text { penempatan yang } \\
\text { memungkinkan } \\
\text { koneksi visual }\end{array}$ \\
\hline \multirow[t]{2}{*}{8} & $\begin{array}{l}\text { DETAIL } \\
\text { a. Detail } \\
\text { bangunan } \\
\text { kurang } \\
\text { mendapatkan } \\
\text { perhatian }\end{array}$ & Ill & $\begin{array}{l}\text { Memberi detail } \\
\text { pada bangunan, } \\
\text { misal penggunaan } \\
\text { tekstur, atau } \\
\text { secondary skin }\end{array}$ \\
\hline & $\begin{array}{l}\text { b. Tidak ada detail } \\
\text { street furniture }\end{array}$ & Well & $\begin{array}{lr}\text { Mendisain } & \text { street } \\
\text { furniture } & \text { yang } \\
\text { menarik } & \\
\text { pedestrian } & \end{array}$ \\
\hline
\end{tabular}

Sumber: Analisis, 2014

\section{Konsep Pedestrian Friendly untuk Pengembangan Fakultas Teknik Universitas Sriwijaya}

Berdasarkan klasifikasi tersebut diatas, dapat dirumuskan beberapa konsep pedestrian friendly yang kontekstual terhadap lingkungan FT Unsri Indralaya, yaitu :

\section{Site Planning}

1. Merenovasi bangunan di lingkungan FT Unsri agar saling berhubungan dan menciptakan ruang luar yang positif

2. Membuat disain jalur pedestrian dan sepeda yang baik

\section{Sirkulasi}

1. Membuat trotoar yang menerus dari satu bangunan ke bangunan lain

2. Membuat rute trotoar dari bangunan pengajaran ke bangunan dekanat serta memanfaatkan jalur penghubung yang sudah ada

3. Membuat rute pedestrian yang terdisain dari pengajaran menuju ke laboratorium

4. Membuat trotoar dengan lebar min $100 \mathrm{~cm}$ agar mampu 
menampung pedestrian dan street furniture

5. Membuat penanda sebagai tempat penyeberangan, berupa cat, pembedaan ketinggian, ataupun material yang unik

6. Membuat tempat penyeberangan yang terdisain dari kantung parkir menuju bangunan

7. Membuat daerah penyangga antar jalur pedestrian dan kendaraan

8. Membuat jalur penghubung antar gedung Studio Arsitektur, gedung Arsitektur dan Gedung Dekanat

9. Membuat jalur penghubung antar Graha Patra Kemika dan bangunan Dekanat

\section{Massa Bangunan}

1. Membuat stimulus visual pada bangunan, dengan cara membuat jalur pejalan kaki yang tertutup, bentuk yang irregular, memberi detail pada sudut bangunan

2. Redisain fasade bangunan agar saling berinteraksi membentuk ruang pejalan kaki

\section{Proporsi}

1. Mendisain dan melebarkan trotoar yang berhadapan dengan bangunan

2. Mengubah ukuran signage sesuai dengan skala manusia, serta menempatkannya dengan baik

\section{Material}

1. Renovasi fasade bangunan dan jalur pedestrian menggunakan material unik dan tekstur khusus

2. Menempatkan street furniture yang terdisain dengan baik

\section{Ritme}

1. Menata ulang bangunan agar saling berkesinambungan

2. Membuat pemecah irama bangunan, berupa entrance yang menarik perhatian atau permainan warna dan kolom pada fasad bangunan

\section{Transparansi}

Merenovasi fasad bangunan terutama pada lantai dasar, agar lebih bersifat transparan untuk memberikan koneksi visual dari ruang luar

\section{Detail}

Memberi detail pada bangunan, misal penggunaan tekstur, atau secondary skin

\section{Kesimpulan}

Konsep pedestrian friendly belum diterapkan pada lingkungan Fakultas Teknik Unsri sehingga pengembangan fisik kawasan kurang berpihak pada pejalan kaki. Tinjauan konsep pedestrian friendly dengan metode Ends-Mean membantu mengkategorikan persoalan mana yang terdefinisi dengan jelas, sehingga mempermudah dalam merumuskan konsep pedestrian friendly yang bersifat terapan langsung di lapangan. Diharapkan dengan adanya pertimbangan konsep ini dalam pengembangan di masa yang akan datang dapat meningkatkan kualitas aktivitas akademik maupun non akademik di lingkungan FT Unsri dan Universitas Sriwijaya secara keseluruhan.

\section{Daftar Pustaka}

Jacobs, A. B. (1993). Great street. Cambridge: MIT Press.

Meyers. (2009). Pedestrian Scale Design Guidelines Manual. Ohio:Meyers Associates.

Rowe, P.G. (1987). Design thinking. Cambridge: The MIT Press. 